\title{
Shakeup for Royal Observatories
}

\section{London}

A ScIEnce and Engineering Research Council (SERC) plan to bring Britain's two separate Royal Observatories under the control of a single, powerful director is dividing UK astronomers. Many staff at the Royal Greenwich Observatory (RGO) in Cambridge and the Royal Observatory, Edinburgh (ROE) believe the new organization will destroy the institutes' traditional autonomy, bringing them more strongly under the influence of SERC's headquarters at Swindon. Given the frequently aired misgivings of SERC's chairman Sir Mark Richmond about the high proportion of the council's budget spent on 'big science', they fear the worst.

Some university astronomers share their colleagues' concern, arguing that the loss of the scientific leadership traditionally given by the two Royal Observatory directors could undermine morale, seriously damaging British astronomy. But others believe changes are long overdue, and say that the new central control could lead to better access to Britain's telescopes for university astronomers. The debate will intensify over the next few months, as SERC searches among its own employees for a suitable candidate for the new job.

The Royal Observatories predate the modern organization of UK science, and were once synonymous with British astronomy. (RGO dates from the seventeenth century, ROE from the eighteenth.) But the growth of a university-based British astronomical community, and the observatories' takeover by SERC in the 1960 s, forced changes.

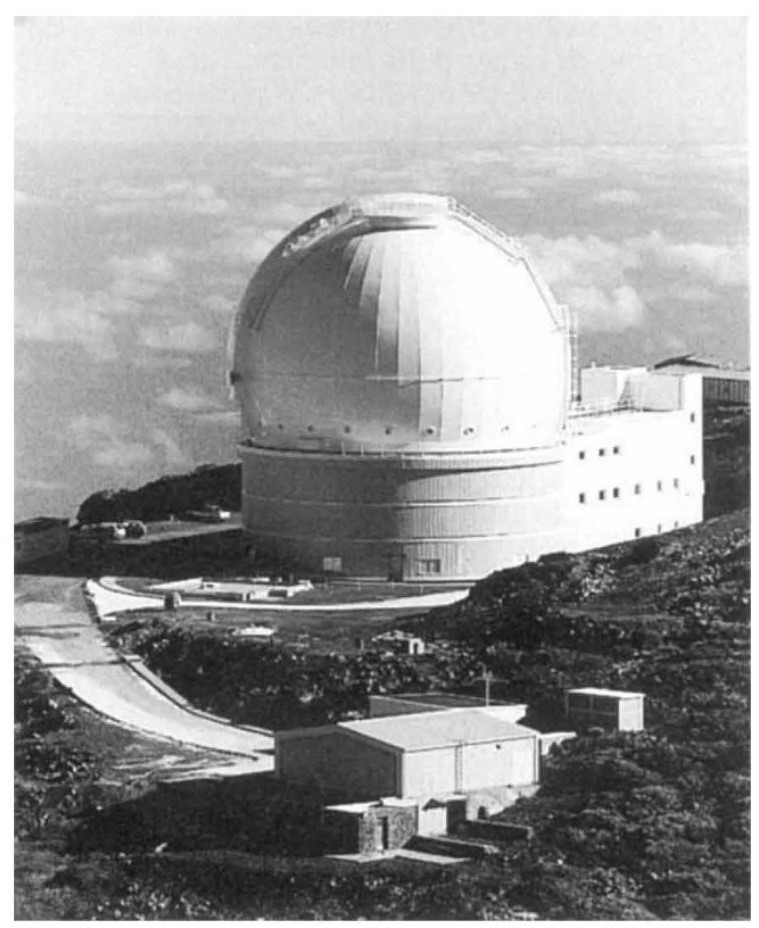

The 4.2-metre William Herschel Telescope at La Palma, in the Canary Islands run by RGO.
Over the past decade, SERC's

policy has been to reduce the observatories' status as premier research centres (the number of staff employed at the two sites has fallen from 341 to 245 since 1985). Today, their main role is to run large telescopes for use by the wider UK astronomical community. For RGO, this means running Britain's optical telescopes, at La Palma, in the Canary Islands, while ROE is responsible for a series of infrared telescopes in Hawaii.

But according to SERC's deputy chairman, Tony Hughes, the separation between the two observatories' roles is now inappropriate. The next major project in British astronomy - the Gemini collaboration with the United States and Canada (see Nature 353, 688; 1991) — is to build two 8-metre telescopes that will observe in both the visible and infrared spectra, cutting across the traditional demarcation between the two Royal Observatories. And

some astronomers say privately that the natural spirit of competition between the two Royal Observatories has not always served British astronomy well.

Some Royal Observatory astronomers view SERC's plans in a much more sinister light, however. As SERC employees, they are unwilling to speak publicly, fearing retribution. But amid dark mutterings about SERC's "management by terror", the fear is that the the new director may not fight strongly for the observatories' interests against a SERC leadership seen by 